Jurnal Teknik Komputer AMIK BSI

Volume 8, No.1, Januari 2022

P-ISSN 2442-2436, E-ISSN: 2550-0120

Akreditasi Ristekdikti, No: 36/E/KPT/2019 (Sinta 4)

DOI: $10.31294 /$ jtk.v4i2

\title{
Rancang Bangun Sistem Pemesanan Seragam Berbasis Web Menggunakan Waterfall Model
}

\author{
Wahyudin $^{1}$, Syamsul Bahri ${ }^{2}$, Umi Kulsum ${ }^{3}$ \\ ${ }^{1,2}$ Uniiversitas Bina Sarana Informatika \\ ${ }^{1}$ e-mail: Wahyudin.whd@bsi.ac.id \\ e-mail: syamsul@bsi.ac.id \\ ${ }^{3}$ Universitas Nusa Mandiri \\ e-mail: umikulsum023@gmail.com
}

\begin{tabular}{ccc}
\hline Diterima & Direvisi & Disetujui \\
$03-01-2022$ & $13-01-2022$ & $17-01-2022$ \\
\hline
\end{tabular}

\begin{abstract}
Abstrak - Website merupakan salah satu layanan yang dapat dipakai oleh pengguna komputer yang terhubung dengan internet. Website memudahkan pengguna komputer untuk berinteraksi dengan pengguna internet lainnya dan menelusuri informasi yang ada di jaringan internet. Jaya Bersama Konveksi merupakan salah satu perusahaan garmen yang bergerak di bidang konveksi. Tujuan dari Penelitian ini adalah membuat website informasi konveksi pada Jaya Bersama Konveksi. Untuk membuat website Jaya Bersama Konveksi dibutuhkan beberapa metode. Pada Penelitian ini metode yang digunakan antara lain studi pustaka, observasi dan wawancara. Website ini dikembangkan dengan bahasa pemrograman PHP dan untuk mengatur database digunakan MySQL.Pada penelitian ini telah dibuat suatu sistem yang memiliki fasilitas seperti informasi profil, produk, lokasi, berita, buku tamu dan sistem pengelolaan data website bagi administrator. Sistem ini dapat dikembangkan lebih lanjut untuk dapat menangani proses yang lebih kompleks, seperti chatting online dengan marketing untuk para customer
\end{abstract}

Kata Kunci: Sistem Pemesanan, waterfall model, Rancang bangun

Abstract - Website is a service that can be used by computer users to connect to the internet. Website is easier for users to interact with computer users browsing the internet and other information on the Internet network. is one garment companies engaged in the convection. The purpose of the final project is to developed website of Jaya Bersama Konveksi.To create the website of Jaya Bersama Konveksi, needed some methods. The methods on research are used, among others, library research and observation. The website was developed PHP and to manage the database was used MySQL.In this case has been created on a system that has facilities such as profile information, products, locations, news, guest book and Web data management for systems administrators. The system can be further developed to be able to handle more complex processes, such as chatting online with the marketing for the customer.

Keywords: Ordering System, waterfall model, Design

\section{PENDAHULUAN}

Perkembangan teknologi informasi yang sangat pesat dewasa ini memberikan banyak kemudahan pada berbagai bidang. Hal ini juga yang menyebabkan munculnya kemajuan pada perangkat lunak dan diimbangi pula dengan kemajuan dan kecanggihan teknologi beserta perangkat kerasnya. Secara langsung ataupun tidak teknologi informasi telah menjadi bagian penting dari berbagai bidang kehidupan. Karena banyak kemudahan yang ditawarkan, teknologi informasi hampir tidak dapat dilepaskan dari berbagai aspek kehidupan manusia. Menurut Kamus Besar Bahasa Indonesia yang dimaksud pemesanan adalah "proses, pembuatan, cara memesan (tempat, barang, jasa dsb) kepada orang lain". Pemesanan merupakan salah satu prosedur yang dilakukan pelanggan (taufik,ermawati 2017).

Saat ini masih ada beberapa instansi yang masih menggunakan sistem konvensional untuk menjalankan proses bisnisnya. begitu juga dengan jaya bersama konveksi, masih menggunakan sistem 
pemesanan seragam secara konvensional, masih terdapat kendala dalam proses bisnisnya.

Untuk menyelesaikan kendala proses bisnis tersebut dapat diselesaikan salah satu caranya dengan teknologi informasi, yaitu proses bisnisnya berupa pemesanan konvensional di konversi menjadi sistem informasi pemesanan seragam berbasis web.

\section{METODOLOGI PENELITIAN}

Metode penelitian adalah serangkaian kegiatan atau cara untuk mendapatkan data atau informasi dari objek yang diteliti. Metode penelitian yang digunakan penulis dalam penelitian ini antara lain model pengembangan sistem dan teknik pengumpulan data.

\section{Teknik Pengumpulan Data}

Metode yang akan digunakan dalam pengumpulan data dan informasi untuk mendukung perancangan ini adalah:

a. Wawancara

Wawancara adalah suatu metode penelitian dengan cara melalukan sesi tanya jawab secara langsung dengan objek penelitian. Dalam metode ini, penulis melakukan wawancara dengan Bapak Sri Heri Cevri selaku pemilik konveksi Jaya Bersama Konveksi, agar informasi yang didapatkan dapat membantu dalam perancangan web yang akan dibangun untuk perusahaan tersebut.

b. Observasi

Metode ini merupakan cara pengumpulan data secara langsung dengan mengamati objek penelitian di Jaya Bersama Konveksi.

c. Studi Pustaka

Penulisan skripsi ini ditunjang oleh beberapa jurnal, buku - buku yang berisi teori-teori yang berkaitan dengan masalah yang dibahas serta catatan-catatan kuliah dan penunjang lainnya. Pada metode ini, penulis mendapat banyak bahan masukan tentang bagaimana merancang atau mengembangan suatu sistem informasi menurut para ahlinya.

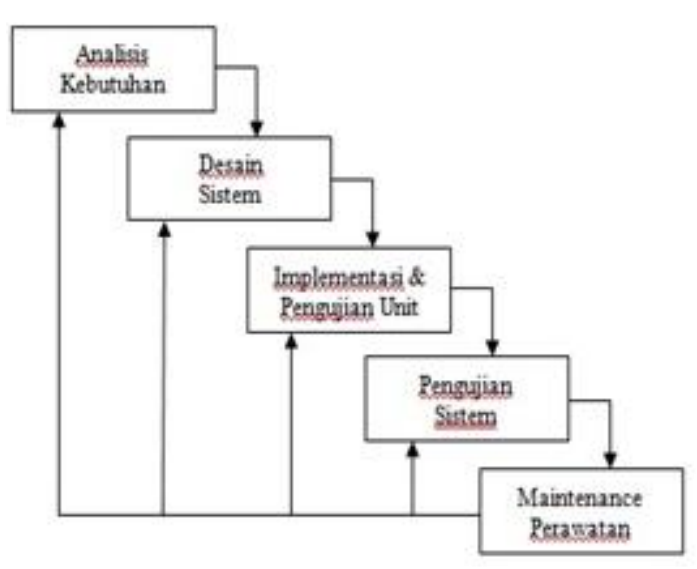

Sumber: Mulyanto (2009:244)

\section{Gambar 1. Waterfall Model}

Sesuai dengan namanya waterfall (air terjun) maka tahapan dalam model ini disusun bertingkat, setiap tahap dalam

model ini dilakukan berurutan, satu sebelum yang lainnya (lihat tanda anak panah). Selain itu dari satu tahap kita dapat kembali ketahap sebelumnya. Model ini biasanya digunakan untuk membuat sebuah software dalam skala besar dan yang akan dipakai dalam waktu yang lama. Tahap - Tahap Dalam Model Waterfall:

1. Requirements Analysis

Seluruh kebutuhan software harus bisa didapatkan pada fase ini, termasuk didalamnya kegunaan software yang diharapkan pengguna dan batasan software. Informasi ini biasanya dapat diperoleh dari wawancara, survey atau diskusi. Informasi tersebut di analisis untuk mendapatkan dokumentasi kebutuhan pengguna untuk digunakan pada tahap selanjutnya.

2. System Design

Tahap ini dilakukan sebelum melakukan coding. Tahap ini bertujuan untuk memberikan gambaran apa yang seharusnya dikerjakan dan bagaimana tampilannya. Tahap ini membantu dalam menspesifikasikan kebutuhan hardware dan sistem serta mendefinisikan arsitektur sistem secara keseluruhan.

3. Implementation

Dalam tahap ini dilakukan pemrograman. Pembuatan software dipecah menjadi modul-modul kecil yang nantinya akan digabungkan dalam tahap berikutnya. Selain itu dalam tahap ini juga dilakukan pemeriksaan terhadap modul yang dibuat, apakah sudah memenuhi fungsi yang diinginkan atau belum. 4. Integration and Testing

Di tahap ini dilakukan penggabungan modul-modul yang sudah dibuat dan dilakukan pengujian. Ini dilakukan untuk mengetahui apakah software yang dibuat telah sesuai dengan desainnya dan masih terdapat kesalahan atau tidak.

5. Operation and Maintenance

Ini merupakan tahap terakhir dalam waterfall model. Software yang telah jadi dijalankan serta dilakukan pemeliharaan. Pemeliharaan termasuk dalam memperbaiki kesalahan yang tidak ditemukan pada langkah sebelumnya.

\section{HASIL DAN PEMBAHASAN}

\section{Tahapan Analisis}

Sistem pemesanan online berbasis web dimana penjual dan pembeli tidak bertatap muka secara langsung. Calon pemesan melakukan pemesanan melalui media browser. Berikut ini spesifikasi kebutuhan dari sistem pemesanan:

Halaman User:

A1. User Dapat Melihat Profil Perusahaan

A2. User dapat melihat produk

A3. User Dapat Melihat Cara Pemesanan 
A4. User dapat melakukan registrasi pelanggan

A5. User dapat mengisi formulir

A6. User dapat login dengan username yang telah di buat

A7. User dapat memesan produk

A8. User dapat melihat informasi penjual (hubungi kami)

Halaman Admin:

B1. Admin dapat mengelola data produk

B2. Admin dapat mengelola data bahan

B3. Admin dapat mengelola data pelanggan

B4. Admin dapat mengelola data pemesanan

B5. Admin dapat mengelola data Pembayaran

B6. Admin dapat mengelola Laporan Pemesanan

B7. Admin dapat mengelola Laporan Pembayaran

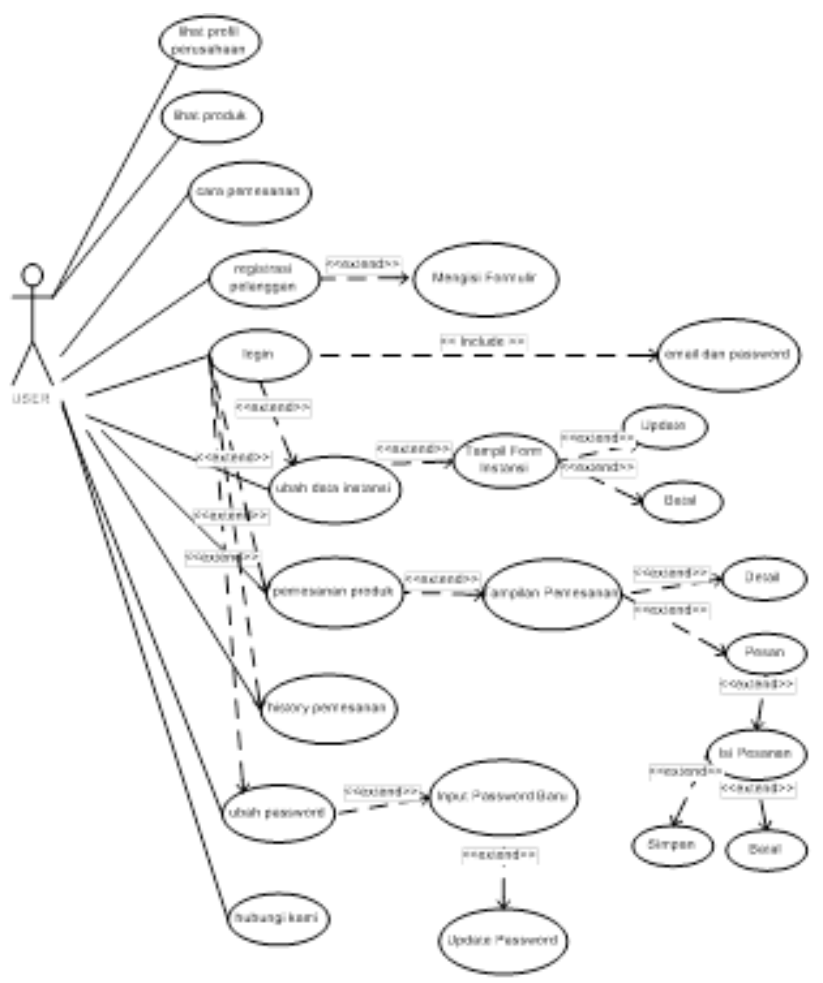

Gambar 2

Use Case Diagram User

\section{Desain}

Pada tahapan desain web e-commerce, penulis menggunakan beberapa tools, database ataupun arsitektur dari software yang digunakan, antara lain : Dreamweaver, tools ini digunakan untuk mendesain interface dari program yang dibuat, form-form dibuat lebih menarik, dan frame yang terintegrasi didalam aplikasi yang dirancang. Untuk menunjang basis data pada aplikasi yang dibuat, penulis menggunakan Apache sebagai software database, dikarenakan banyak fitur dalam Apache dan lebih mudah dalam pengaturan sistem database-nya. Selain menggunakan Apache sebagai database, penulis juga menggunakan aplikasi Apache web server untuk mem-publish web yang dirancang.
Berikut penggambaran database yang digunakan agar program ini dapat di aplikasikan dengan baik

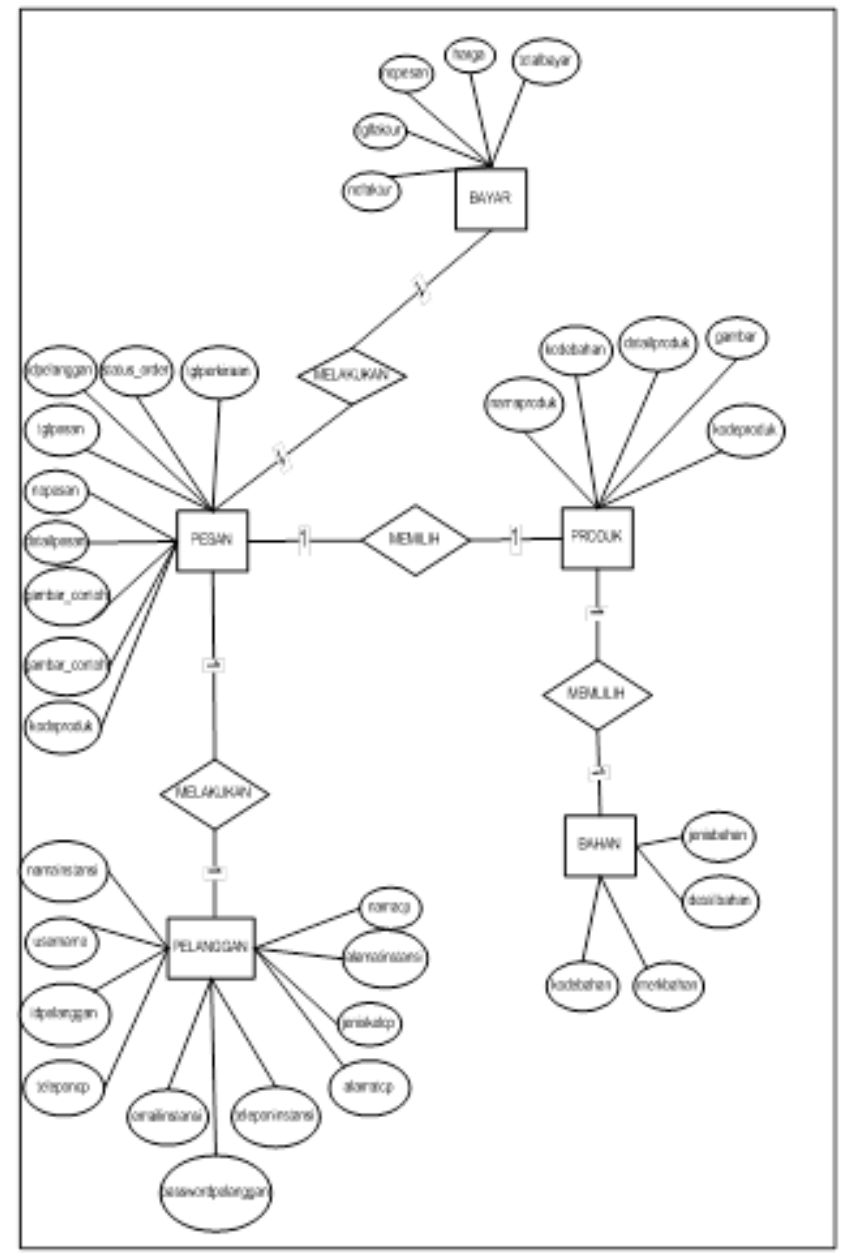

Gambar 3

Entity Relationship Diagram Pemesanan

\section{Database}

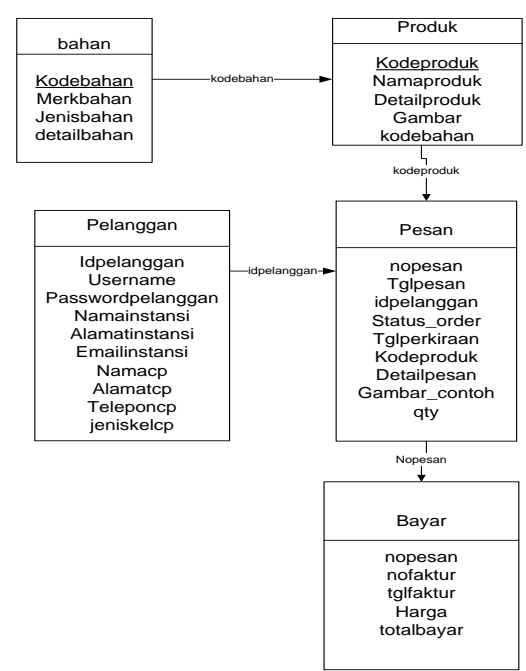




\section{Gambar 4 \\ Logical Record Structure Pemesanan \\ 4. User Interface}

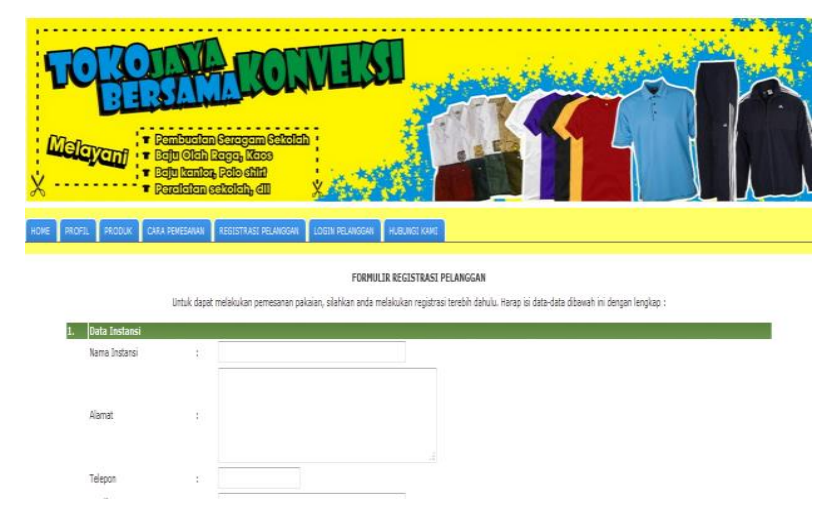

Gambar 5

Tampilan Form Registrasi Konsumen

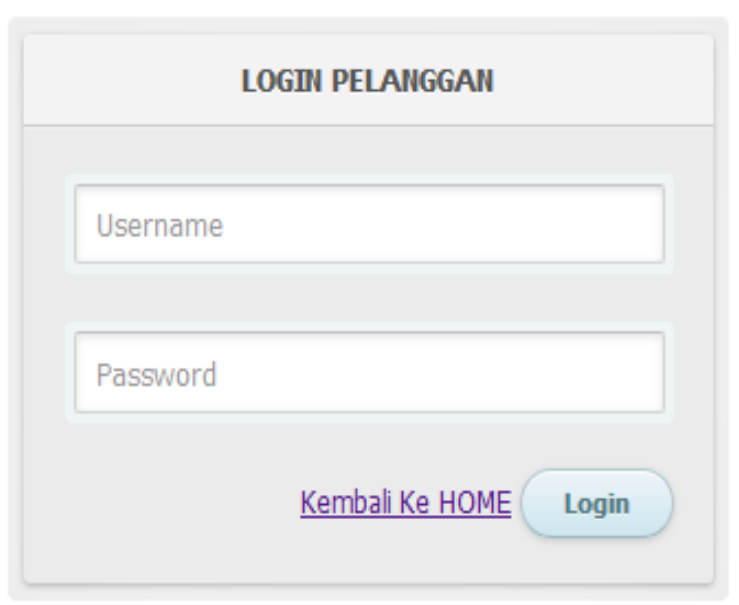

Gambar 6

Tampilan Form Login

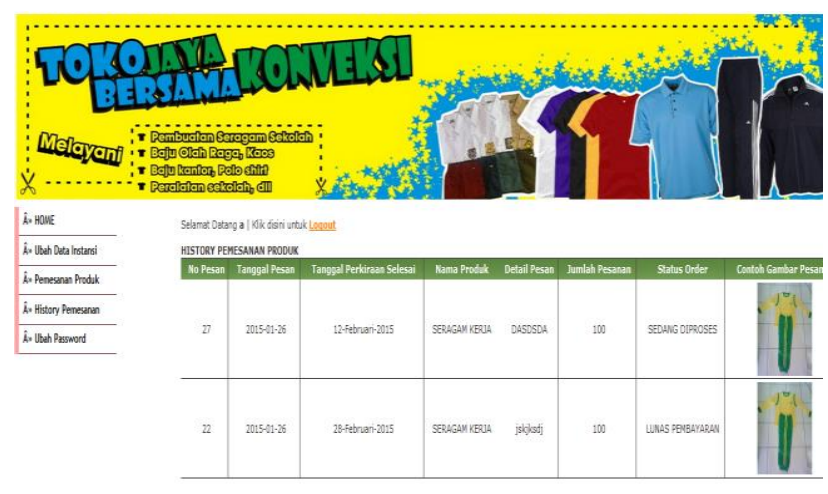

Gambar 7

Tampilan Form History Pemesanan

Tabel 1. Hasil Pengujian Black Box Testing Form Login

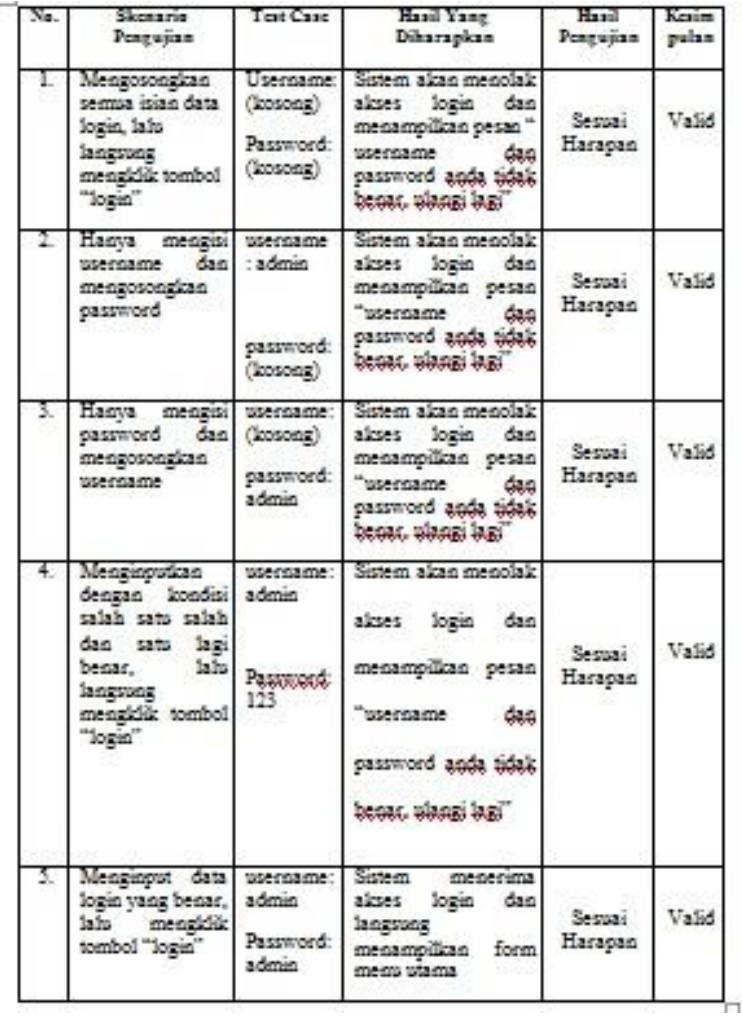

\section{KESIMPULAN}

Setelah penulis memperhatikan uraian-uraian dari bab-bab sebelumnya dapat diambil beberapa kesimpulan di antaranya :

1.Dengan membuat website pada Jaya Bersama Konveksi ini akan memudahkan setiap pengunjung atau calon customer untuk mendapatkan semua informasi perusahaan tersebut.

2.Dengan membuat website pada pada Jaya Bersama Konveksi akan lebih mudah menyampaikan informasi mengenai model dan berbagai informasi terkini yang dapat langsung diupdate diweb.

3.Dengan membuat website pada pada Jaya Bersama Konveksi ini dapat mengurangi biaya promosi dengan hasil yang tetap optimal.

\section{REFERENSI}

Andi Taufik , Ermawati. Perancangan Sistem Informasi Pemesanan Pentas Seni Berbasis Web Pada Sanggar Seni Getar Pakuan Bogor. IJSE - Indonesian Journal on Software Engineering.

Arifin, Zainal. 2010. Pembuatan Perangkat Lunak Aplikasi Pemesanan dan Penjualan Sepeda Motor. Samarinda. Jurnal Informatika Mulawarman, FMIPA Universitas Mulawarman, Vol. 3 No. 3, September 2010:39- 55

Dermawan, Deni dan Fauzi, Nur Kunkun, 2013. Sistem Informasi Manajemen. Bandung : PT. Remaja Rosdakarya. 
Dukom, Master. 2011. Menjadi Master Website Dalam Hitungan Menit. Bekasi : $\quad$ Media Komputer.

Arifin, Ginanjar, Gungun. Deddy, Asep dan Satria, Eri. 2013, Pengembangan Sistem Informasi Pemesanan Kamar Hotel Berbasis Web Menggunakan Metodologi Rapid Application development. ISSN 23027339. Garut: Jurnal Algoritma Sekolah Tinggi Teknologi Garut, Vol. 10 No. 1 2013:1 - 9

Jogiyanto HM. 2008.Sistem Teknologi Informasi Edisi III. Yogyakarta: Andi.

Kusrini. 2007. Strategi Perancangan Dan Pengelolaan Basis Data. Yogyakarta : Andi

Madcoms. 2013. Kupas Tuntas Adobe Dreamweaver CS6 Dengan Pemprograman PHP dan Mysql. Yogyakarta : Andi.

Master.com. 2012. Menguasai PHP dan Mysql. Jakarta : Kuncikom.

Mulyanto, Agus. 2009. Sistem Informasi Konsep \& Aplikasi. Yogyakarta: PustakaPelajar.
Pressman, Roger S. 2005. Software Engineering. New York: The McGrwa-Hill Companies, Inc.

Sibero, Alexander F.K. 2011. Kitab Suci Web Programing. Yogyakarta : Mediakom.

Supriyanto, Antok. Dan Sukma, Bre. 2008. Sistem Informasi Manajemen Pemesanan Makanan Cepat Saji Melalui Internet Dengan Multi Outlet. Yogyakarta. ISSN 1979-2328. Seminar Nasional Informatika 2008, STIKOM Surabaya, Mei 2008:342 - 348

Tandjung, Jenu Widjaja, Prayogo Teguh dan Prabowo Adi. 2013. Stop Promotion Start Communication. Jakarta : PT. Elex Media Komputindo.

Sutanta, Edhy. 2011. Basis Data dalamTinjauan Konseptual. Yogyakarta: Andi

Widodo, Prabowo Pudjo dan Herlawati. 2011. Menggunakan UML. Bandung: Informatika. 